\title{
Geographic variation in decoration selectivity of Micippa platipes and Tiarinia cornigera in Japan
}

\author{
Kristin M. Hultgren ${ }^{1, *}$, Phan Due Thanh ${ }^{2}$, Michiko Sato ${ }^{3}$ \\ ${ }^{1}$ Department of Evolution and Ecology, University of California, Davis, One Shields Avenue, Davis, California 95616, USA \\ ${ }^{2}$ Faculty of Biology and Agriculture, Hanoi University of Education, 136 Xuan Thuy Street, Cau Giay, Hanoi, Vietnam \\ ${ }^{3}$ Seto Marine Biological Laboratory, Kyoto University, Shirahama-cho, Wakayama, 649-2211, Japan
}

\begin{abstract}
Relatively few studies have compared behavioral variation of more than one species among different locations; yet examining geographic variation in behavior in a comparative context is crucial to help elucidate the generality of geographic patterns. We studied geographic variation in decoration preferences for 2 spider crabs (Brachyura: Majoidea), Micippa platipes and Tiarinia cornigera, which co-occur in intertidal areas along the coast of Japan. Both M. platipes and T. cornigera primarily feed on algae and use them for 'decoration' (i.e. attach them to hooked setae on their carapace). We tested whether individuals from 3 locations along the east coast of Japan differed in their decoration and consumption selectivity for certain algae in the field, and also tested decoration and consumption preferences of $M$. platipes in laboratory assays. At the 2 more northern locations, both species showed little selectivity among algae, primarily using them for decoration in proportion to their abundance. Conversely, at the southern location, M. platipes exhibited strong preferences for the alga Hypnea pannosa in both field and laboratory assays, and both crab species strongly avoided the alga Corallina pilulifera. Using both an overall selectivity index $\left(\mathrm{SE}_{\mathrm{o}}\right)$ and a proportional selectivity index (PSE) calculated for each alga, we compared algal use by the crabs vs. algal availability at the 3 locations. Both indices indicated that both species were more selective (had stronger preferences or avoidances of available algae) at the southern location than at the 2 more northern locations. Potential factors driving this latitudinal gradient in selectivity include seasonal and geographic variability in both decoration availability and crab decoration preferences.
\end{abstract}

KEY WORDS: Decorator crab · Geographic variation · Micippa platipes · Tiarinia cornigera • Proportional selectivity index $\cdot \mathrm{PSE} \cdot$ Overall selectivity index $\cdot \mathrm{SE}_{\mathrm{o}} \cdot$ Decoration selectivity

\section{INTRODUCTION}

Although comparative research on behavioral evolution has often relied on characterizations of behavior based on a single population (Foster 1999), several studies have demonstrated substantial intraspecific variation in behavior in terrestrial (Downes \& Adams 2001), aquatic (Endler \& Houde 1995, Foster 1995) and marine (Fawcett 1984, Stachowicz \& Hay 2000, Trussell 2000, Sotka \& Hay 2002, Sanford et al. 2003) systems. Such intraspecific variation in behavior, either as a result of phenotypic plasticity (Trussell 2000) or due to underlying genetic differences between popu- lations (Sanford et al. 2003, Sotka et al. 2003), has the potential to affect local population and community structure (Trussell et al. 2003, Werner \& Peacor 2003). An understanding of the full range of behavioral variation within a species is critical for evaluating the adaptive significance of behavioral differences between species.

Many marine organisms depend on other 'host' organisms for feeding and/or habitat, and such interactions can often vary within a species. This variation can include shifts to other hosts (e.g. as the preferred host becomes more rare), and can also include shifts in niche breadth (increases or decreases in the number of 
hosts utilized). Although specialization on 1 host is common for many tropical species (MacArthur 1972), species that span a latitudinal gradient often exhibit variation in host preferences and subsequent variation in niche breadth. For instance, Stachowicz \& Hay (2000) showed that individuals of the decorator crab Libinia dubia from southern locations exhibited more host specialization (utilization of a host for decoration) than L. dubia from northern locations. In this case, preference for a single decoration material in southern latitudes primarily helped L. dubia avoid predation, but increased specialization on a host could potentially influence other interactions (e.g. competition for food, encounters with potential mates), with important implications for evolution.

In cases where animals utilize several hosts, preference for a particular host can depend not only on host quality (e.g. higher nutritional content) but also on the relative abundance of the preferred host(s) in the habitat (Underwood et al. 2004). In the present study, we use an ecological definition of preference, whereby an organism's use of an acceptable host is compared to the organism's availability. We define 'preference' for a particular host as utilization that is greater than that predicted based on availability. Conversely, 'avoidance' is when utilization of an acceptable host (e.g. one it may utilize in some contexts) is less than that predicted based on availability. Thus, preference and avoidance in this sense are not independent values, but are realized products of an organism's intrinsic preferences for a host, the relative abundance of the host, and the availability of other acceptable hosts in the field. We also use the term 'selectivity' to refer to the overall differences between use and availability of several materials, whereby 'selective' individuals have strong avoidances and/or preferences for certain materials, and 'non-selective' individuals utilize materials in proportion to their availability.

Decorator crabs (Brachyura: Majoidea) are characterized by a unique type of interaction (decorating behavior) that involves attaching items from their habitat such as algae or invertebrates (as well as detritus) to hooked setae on their carapace (Wicksten 1993). It is generally assumed that this behavior visually or chemically camouflages these crabs from predators (Wicksten 1993), although some authors have suggested that decoration may serve as a form of food sequestration (Kilar \& Lou 1986, Woods \& McLay 1994). Decoration has been shown to reduce predation in at least 2 species, Libinia dubia (Stachowicz \& Hay 1999) and Tiarinia cornigera (Thanh et al. 2003). Crabs often vary in their choice of decoration materials, and while several species of decorator crab prefer to specialize on certain decoration materials (Stachowicz \& Hay 1999, Cruz-Rivera 2001), strong preferences can vary geo- graphically or seasonally depending on availability of the decoration material (Sato \& Wada 2000, Stachowicz \& Hay 2000). Examining such variation in different contexts can provide important information on the adaptive evolution of such behaviors.

In this study, we examined geographic variation in decoration preferences and avoidances in the decorator crabs Micippa platipes (Majoidea: Mithracidae) and Tiarinia cornigera (Majoidea: Majidae) among 3 locations, spanning approximately $550 \mathrm{~km}$, along Japan's eastern coast. We assessed decoration material (i.e. host; hereafter referred to as 'decoration') selectivity of these 2 species using both field surveys and laboratory choice experiments, and we discuss trends in selectivity in the context of among-location differences in availability of decoration material, seasonal variability in decoration preferences and avoidances, and latitudinal gradients in niche width.

\section{MATERIALS AND METHODS}

Natural history. Micippa platipes and Tiarinia cornigera (hereafter Micippa and Tiarinia) are found in mid-intertidal pools on the eastern coast of Japan, from Tokyo Bay southwards to northern Australia (Sakai 1965, Sato \& Wada 2000). Both species bear hooked setae over the majority of their carapace, and they decorate these setae with small turf algae found in the intertidal (Dudgeon 1980, Sato \& Wada 2000). Species composition and abundance of algae in this region shifts seasonally (Kennish 1997, Sato \& Wada 2000); algal coverage is generally lowest in the summer, when intertidal areas are dominated by small and/or juvenile turf algae, and highest in winter, when arborescent brown algae such as Sargassum spp. dominate. In Shirahama, Japan (where most of the previous studies on these crabs have been done), decoration utilization in Micippa and Tiarinia shifts seasonally, and Micippa decoration utilization in particular closely tracks seasonal changes in algal availability (Sato \& Wada 2000). Decoration significantly reduces predation of Tiarinia by predators such as puffer fish (Thanh et al. 2003).

In this study, Micippa and Tiarinia were examined in summer 2002 at 3 locations along the eastern coast of Japan (Fig. 1): Kochi (Usa Marine Biological Institute of Kochi University, Kochi Prefecture, $133^{\circ} 27^{\prime} \mathrm{W}$, $33^{\circ} 27^{\prime} \mathrm{N}$ ), Shirahama (Tanabe Bay) (Seto Marine Biological Laboratory of Kyoto University, Wakayama Prefecture, $33^{\circ} 41^{\prime} \mathrm{N}, 135^{\circ} 20^{\prime} \mathrm{W}$ ); and Shimoda (Oura Bay) (Shimoda Marine Research Center, University of Tsukuba, Shizuoka Prefecture, $34^{\circ} 40^{\prime} \mathrm{N}, 138^{\circ} 57^{\prime} \mathrm{E}$ ). All 3 locations consist of intertidal rocky benches, dominated during the summer season by turf-like species 


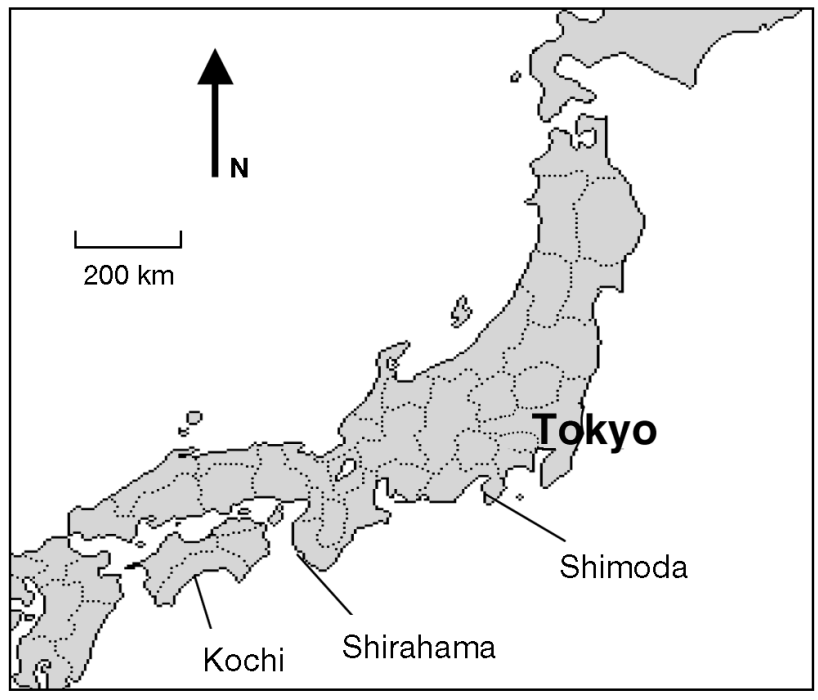

Fig. 1. The 3 study sites (Shimoda, Shirahama and Kochi) in Japan

including red (Hypnea spp., Corallina pilulifera, Acanthophora spicifera, Laurencia sp., Jania spp.), brown (juvenile Padina minor, Sargassum spp.), and green (Ulva spp.) algae.

Field surveys. To measure decoration preferences and avoidances of crabs in the field at each location, we compared decoration on individual crabs with the relative abundance of algae at each of the 3 locations in July and August 2002. Since crabs were wellcamouflaged, we avoided visual collection biases by utilizing 'tactile search' methods, i.e. by intensively running our hands over algal turf in long transects along the species' distributional range (Sato \& Wada 2000). Abundances of both crabs varied between field locations, although we tried to collect similar numbers of Micippa (Kochi, $\mathrm{n}=23$; Shirahama, $\mathrm{n}=31$; Shimoda, $\mathrm{n}=24$ ), and Tiarinia (Kochi, $\mathrm{n}=9$; Shirahama, $\mathrm{n}=17$; Shimoda, $\mathrm{n}=18$ ) for assessments of field decoration. However, sample sizes of Tiarinia were limited since these crabs were rare at some field sites, and to avoid pseudoreplication we used different sets of crabs for field and laboratory preference tests. We recorded carapace width (CW), carapace length (CL) and sex of each crab collected in the field. In the laboratory, the crabs were stripped of decoration and decoration materials were identified under a dissecting microscope, blotted dry, and wet-weighed. We quantified local algal availability at each location by assessing percent cover in 18 haphazard quadrats $(40 \times 40 \mathrm{~cm}$, with a $10 \mathrm{~cm}^{2}$ grid) along the same transects from which the crabs were collected. Since both species rarely use drift algae, and have small homing ranges (range $<1.1 \mathrm{~m} ;$ M. Sato unpubl. data), we are confident that the transects spanned the full range of algae a crab was likely to encounter, including algae in crevices. In general, we used algal quadrats $(n=18)$ that spanned the vertical ranges of the crabs, but in Shimoda, Tiarinia's range encompassed more vertical range than Micippa, and we therefore included 6 additional quadrats from low intertidal areas ( $\mathrm{n}=24$ total) to determine algal availability.

At each location, we determined if crabs had decoration preferences or avoidances for algae by comparing availability of each alga in the field (mean proportion of an alga relative to total mean algal cover) to utilization as a decoration material (mean proportion of an alga relative to total decoration mass) by crabs. We used percent cover as a measure of algal availability since turf algae dominate algal cover in the summer, providing in essence a 2-dimensional surface for crabs to 'sample' for decoration and food. Although this necessitated direct comparisons of alga wet-mass (crab utilization) with alga percent cover (field availability), the species of algae used in the study had similar morphologies (low-growing turf), and relative percent cover/wet-mass relationships were similar. Although we use percent cover data in all graphs, we also converted percent cover data to biomass data using formulae (Kennish 1997) published for similar species of algae in Hong Kong that were qualitatively similar to the volume-mass conversion factors calculated for Shirahama algae (M. Sato unpubl. data), and ran all calculations and statistics using percent mass data.

At each location, a crab species was considered to prefer a certain alga when its utilization was significantly higher than its availability, and was considered to avoid an alga when its utilization was significantly lower than its availability. Since algal abundances were calculated as percentages, running analyses with bare space included did not quantitatively change results. Use and availability data violated assumptions of parametric tests, so we used non-parametric Wilcoxon signed-rank tests computed by JMP 5.1 (SAS Institute) to compare availability vs. utilization of a certain alga by Micippa and Tiarinia at each location. For each crab species, we performed these comparisons for the most dominant species of algae (e.g. with high utilization as decoration and/or high availability) at each location, and used sequential Bonferroni-corrected $\alpha$-values (Rice 1989) to determine which algae were preferred or avoided at each location by a particular crab species (although results were nearly identical when $\alpha$-values of 0.05 were used). To compare preference or avoidance of a certain alga by a crab species among locations, we also calculated and compared proportional selectivity indices for particular algae (see 'Selectivity calculations' below).

Laboratory assays. We conducted laboratory assays of decoration and food selectivity with Micippa, 
whereby we transported Micippa from the Kochi and Shimoda locations back to the Seto Marine Biological Laboratory in Shirahama. We measured feeding and decoration selectivity for crabs from all 3 locations ( $\mathrm{n}=$ 13 to 15 individuals per location). For these experiments, we offered crabs 4 types of algae abundant in Shirahama: Hypnea pannosa, juvenile Padina minor, Acanthophora spicifera and Sargassum thunbergii, limiting the number of algae choices to make sure the crabs were able to make effective comparisons (Raffa et al. 2002). Corallina pilulifera could not be used because of low local abundance in Shirahama. After acclimating crabs for 12 to $24 \mathrm{~h}$ in running seawater, we stripped them of field decoration, placed them in $24 \mathrm{l}$ flow-through tanks, and offered them identical amounts of each species of algae $(250 \pm 50 \mathrm{mg})$ for the $36 \mathrm{~h}$ duration of the experiment. We presented algae on a $2.5 \mathrm{~cm}^{2}$ piece of Velcro, both to control surface area availability and to simulate turf conditions in the field. Control tanks (identical set-up but with no crabs) were used to estimate natural mass changes in algae over the experiment. We calculated mass of algae eaten using the following equation adapted from Stachowicz \& Hay (2000): $M_{\mathrm{E}}=\left[M_{\mathrm{S}} \times\left(C_{\mathrm{r}} C_{\mathrm{s}}^{-1}\right)\right]-\left(M_{\mathrm{D}}+\right.$ $M_{\mathrm{R}}$ ), where $M_{\mathrm{E}}=$ mass of algae eaten, $M_{\mathrm{S}}=$ starting mass algae, $C_{\mathrm{r}}$ and $C_{\mathrm{s}}=$ remaining and initial masses of algae in control tanks, respectively, $M_{\mathrm{D}}=$ mass used in decoration, and $M_{\mathrm{R}}=$ mass remaining in tank. Because crabs never consumed (or used for decoration) 100\% of any of the algae in these assays, we assumed that they did not have to make a choice between decorating with an alga and eating it (i.e. decorating with an alga did not make the alga inaccessible for consumption and vice versa).

We performed additional preference experiments with local algae in locations where crab species showed strong field decoration preferences or avoidances. As algal species composition varied among sites, we were not able to use the same species of algae in all tests (e.g. Jania adharens was more common than $J$. radiata in Kochi, Hypnea charoides replaced H. pannosa in Shimoda). In Kochi, we offered Micippa ( $\mathrm{n}=18$ ) a choice among Gelidium sp., H. pannosa, Corallina pilulifera, Dictyota dichotoma, and J. adharens in a $5 \mathrm{~h}$ decoration assay. In Shimoda, we offered Tiarinia $(\mathrm{n}=16)$ a choice of Cladophora sp., $D$ dichotoma, C. pilulifera, H. charoides, and Pterocladiella sp. in a $24 \mathrm{~h}$ decoration assay.

To calculate if a crab preferred or avoided a certain alga, we compared, in the laboratory, the availability of the alga ( 0.25 for each alga) to crab utilization of the alga for decoration and food, using Neu's nonparametric test (Neu et al. 1974). Neu's test (similar to Friedman's test) examines non-independent variables such as preferences and avoidances, and gives the lowest Type II error rates based on our experimental design (Alldredge \& Ratti 1986, 1992). To examine differences in preference or avoidance of an alga among locations, we calculated and compared proportional selectivity indices (see next subsection).

Selectivity calculations. In order to examine general differences in decoration selectivity among locations, we determined how selective crabs from each location were using a selectivity index $\left(\mathrm{SE}_{\mathrm{o}}\right)$, based on Ivlev's electivity index $\left(E_{i}\right.$, Ivlev 1961). For each species of crab, at each location, we calculated:

$$
\mathrm{SE}_{\mathrm{o}}=\sum_{i=1}^{k}\left|r_{i}-p_{i}\right|
$$

where $r_{i}=$ mean utilization of Alga $i$ for decoration by crabs at a location, $p_{i}=$ mean availability of Alga $i$ in the field, and $k=$ number of types of algae available.

$\mathrm{SE}_{\mathrm{o}}$ is a composite index of how selective crabs from any one location ('population') are as a whole in choosing decoration materials, encompassing both preferences and avoidances and minimizing inter-individual variation. $\mathrm{SE}_{\mathrm{o}}$ is bounded by 0 and 2 : when $\mathrm{SE}_{\mathrm{o}}=0$, the population uses every alga in proportion to its abundance (mean use = mean availability); as $\mathrm{SE}_{\mathrm{o}}$ approaches 2 , the population uses the most rare alga (mean use $>>$ mean availability) and avoids all other algae (mean use $<<$ mean availability). Since $\mathrm{SE}_{\mathrm{o}}$ is not sensitive to the number of materials (i.e. algae), we calculated $\mathrm{SE}_{\mathrm{o}}$ for each species at each location (i.e. populations) using data on utilization and availability for all algae present.

If a crab species strongly preferred or avoided a certain alga at a location, we also statistically compared selectivity (preference and/or avoidance) of that alga among locations. To do this, we calculated 'proportional selectivity' (PSE) scores for individual crabs $(j)$ and algae (i) at each location:

$$
\mathrm{PSE}_{i j}=r_{i j}-p_{i}
$$

where $r_{i j}=$ proportion utilization of Alga $i$ as decoration by Crab $j$ and $p_{i}=$ mean availability of Alga $i$, or mean percent cover of $i$ in the field.

This index is also based on Ivlev's (1961) $E_{i}$, where $E_{i}=\left(r_{i}-p_{i}\right) /\left(r_{i}+p_{i}\right)$, but is designed to compare the relative selectivity of an individual for an alga given the availability of that alga in the field. For example, if Alga $i$ availability $=0.0001 \%\left(p_{i}=0.0001\right)$ and is never used by Individual $j\left(r_{i j}=0\right)$, Ivlev's $E_{i j}=-1$ (strong avoidance of the rare Alga $i$ ). If Individual $j$ uses Alga $m 90 \%$ of the time $\left(r_{m j}=0.9\right)$, but availability of $m=5 \%$ $\left(p_{m}=0.05\right)$, then $E_{m j}=0.8947$ (strong preference for the rare Alga $m$ ). As naturalists, we might intuitively say that an animal's preference for Alga $m\left(E_{m j}=0.8947\right)$ is stronger (and more biologically significant) than its avoidance of Alga $i\left(E_{i j}=-1\right)$, yet the magnitude of the 
2 indices are similar. The $\mathrm{PSE}_{i j}$ corrects for this; calculating PSE values using this example, $\mathrm{PSE}_{i j}=-0.0001$ (weak avoidance of rare Alga $i$ ), and $\mathrm{PSE}_{m j}=0.85$ (strong preference for rare Alga $m$ ).

PSE is bounded by -1 and 1: as $\operatorname{PSE}_{i j}$ approaches 1, Individual $j$ exclusively uses a rare Alga $i$ (use $>>$ availability); as $\mathrm{PSE}_{i j}$ approaches -1, Individual $j$ never uses a common Alga $i$ (use $<<$ availability). For each crab species, we calculated PSE scores for an alga if analyses of availability vs. utilization indicated a significant preference or avoidance of the alga (and thus a nonzero PSE) at any one of the 3 locations, either in the field surveys or in laboratory assays. For each crab species, we then compared PSE scores using a KruskalWallis test computed by SPSS 10.0 to determine if there were differences in the PSE for a particular alga among the 3 locations (although results were qualitatively similar using parametric ANOVA). If there were significant differences among locations, we used nonparametric multiple comparison tests, designed for use with Kruskal-Wallis tests, to see which pairs of locations differed (Conover 1999).

To test for demographic and behavioral differences between locations, we compared crab size (mm CW) and decoration quantity (decoration mass per crab area, or $\mathrm{mg} \mathrm{mm}^{-2}$ ) of each crab at each location. We used a log transformation to meet the assumptions of parametric tests and analyzed data using a 1-way ANOVA (JMP 5.1). Least-squared location means for crab size and decoration quantity were compared using Tukey-Kramer post-hoc tests (Steel et al. 1997). In addition, since size has been known to affect decoration quantity (Stachowicz \& Hay 1999, Cruz-Rivera 2001), we checked to see if there were significant linear relationships between size and decoration quantity for each species, both within locations and across all locations. Untransformed means are presented in the results and figures.

\section{RESULTS}

\section{Variation in field decoration preferences}

Decoration selectivity in Micippa and Tiarinia varied among the 3 locations (Fig. 2). In Kochi, Micippa were very selective; they preferred Hypnea pannosa $(\mathrm{p}<$ $0.0001)$ and Jania radiata ( $\mathrm{p}=0.0016)$ in field surveys, and avoided the dominant alga (Corallina pilulifera) at the location $(p<0.0001)$. Although sample sizes were small, Tiarinia showed similar patterns in Kochi, where they strongly avoided the dominant alga $C$. pilulifera ( $p<0.0001)$. In Shirahama, the middle location, Micip$p a$ and Tiarinia decorated with several species of algae in proportion to their abundance and had no significant

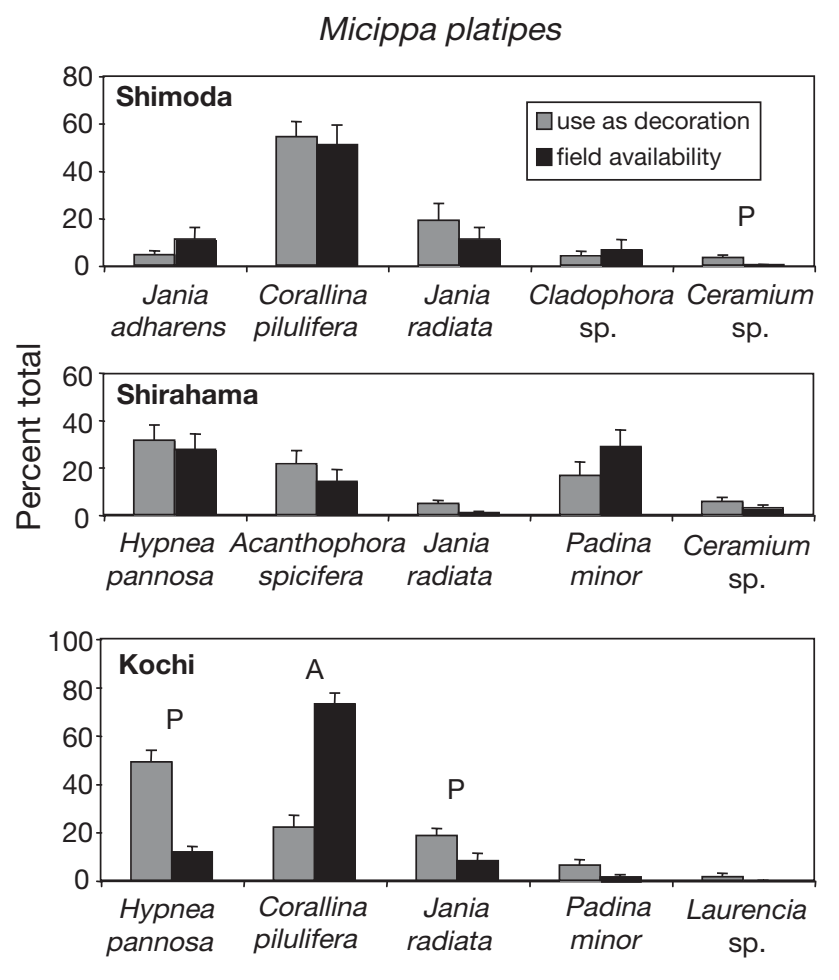

Tiarinia cornigera
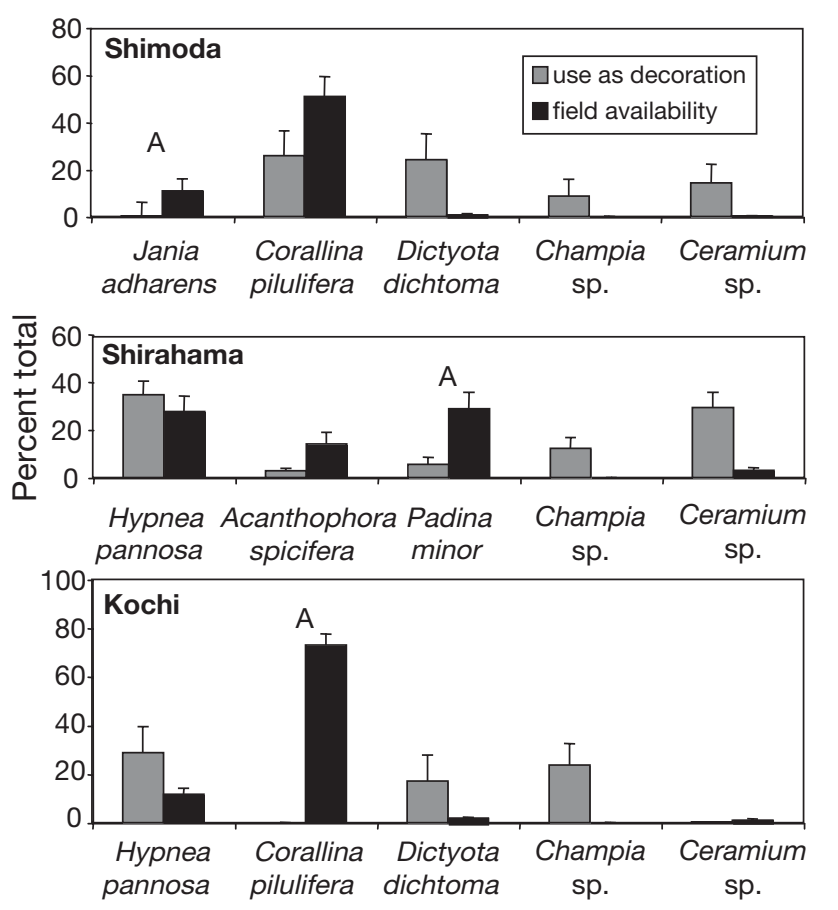

Fig. 2 Micippa platipes and Tiarinia cornigera. Field decoration preferences at 3 locations in Japan, showing decoration utilization by crab (percent of total decoration mass) and field alga availability (percent of total algal cover). P: significant preference for particular alga for decoration; A: significant avoidance of particular alga for decoration 
preferences or avoidances. At Shimoda, the most northern location crabs also had significant (but low magnitude) preferences and avoidances; Micippa preferred to decorate with Ceramium sp. $(p=0.0005)$, and Tiarinia avoided Jania adharens ( $p=0.0009)$, but crab selection otherwise closely tracked algal availability. Results were quantitatively and statistically similar when algal availability (\% cover) was converted to biomass (\% mass). As C. pilulifera was slightly heavier than the other algae (higher $\mathrm{g} \mathrm{m}^{-2}$ ) and thus more 'available', converting algal availability to biomass accentuated avoidance of $C$. pilulifera and preference for Hypnea pannosa (data not shown), although on average algal availability values only changed by $\pm 1.5 \%$.

Additional laboratory assays performed in Kochi and Shimoda using local algae corroborated field surveys (Fig. 3). In Kochi, Micippa avoided Corallina pilulifera $(\mathrm{p}<0.05)$ and Dictyota dichotoma $(\mathrm{p}<0.05)$, and preferred Hypnea pannosa ( $\mathrm{p}<0.05)$. In Shimoda, Tiarinia avoided Pterocladiella sp. $(\mathrm{p}<0.05)$, but otherwise showed no preferences or avoidances.

Laboratory assays comparing Micippa feeding and decoration among locations supported trends in the field at the 3 locations (Fig. 4). Again, Micippa from Kochi preferred to decorate with Hypnea pannosa $(\mathrm{p}<0.05)$, while Micippa from Shirahama and Shimoda did not have significant decoration preferences. Crabs from all locations avoided decorating with Acanthophora spicifera $(\mathrm{p}<0.05)$. In general, the alga preferred for decoration was not preferred for consumption (Fig. 4). Micippa from all 3 locations avoided consuming Sargassum thunbergii $(p<0.05)$, and Shimoda crabs preferred to consume Padina minor $(\mathrm{p}<0.05)$.

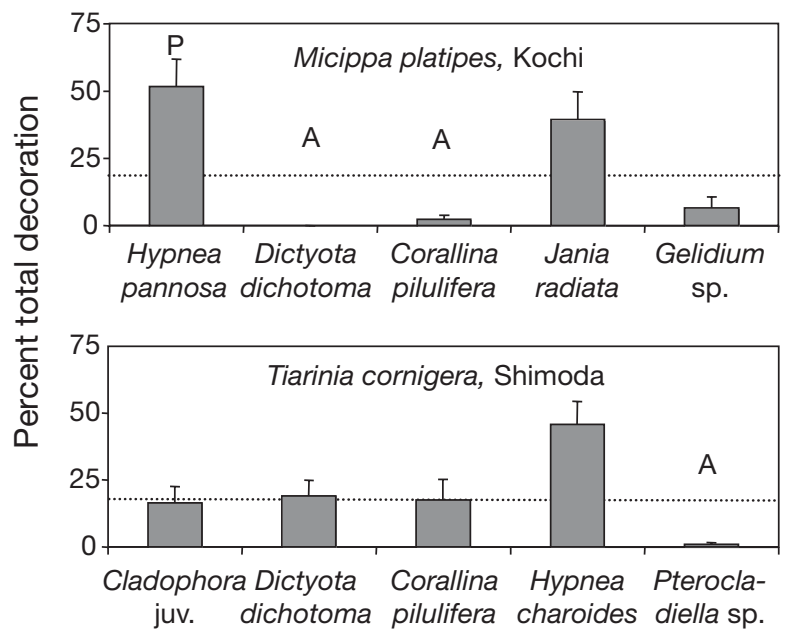

Fig. 3. Micippa platipes and Tiarina cornigera. Laboratory preference tests using local algae for Micippa in Kochi and Tiarinia in Shimoda. Dotted line indicates algal availability during assay ( $20 \%$ for each algae); P: significant preference for particular alga for decoration; A: significant avoidance of particular alga for decoration

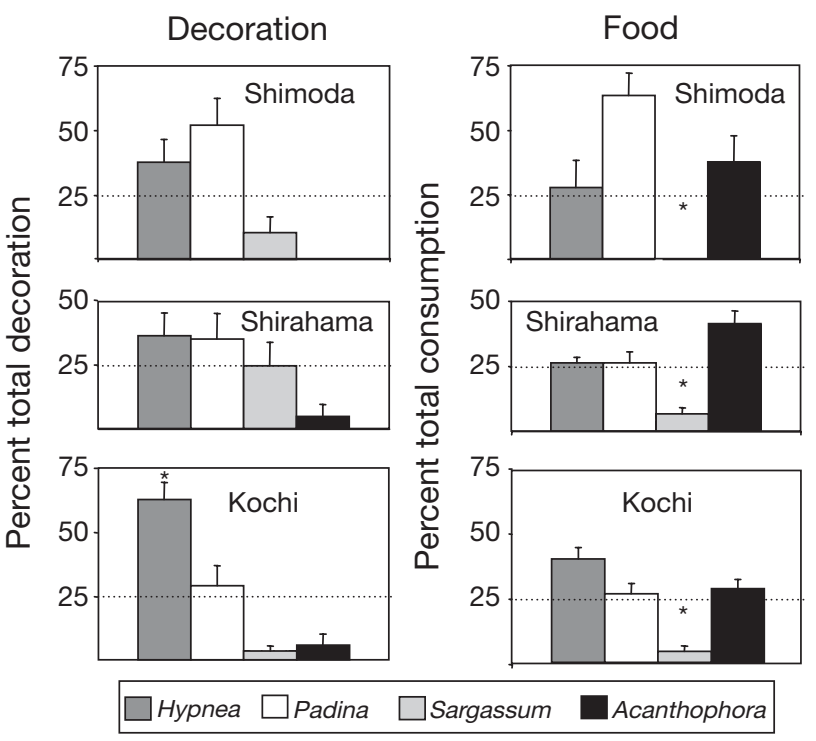

Fig. 4. Micippa platipes. Decoration preferences and food preferences for 4 types of algae. Dotted line indicates availability during assay ( $25 \%$ for each algae). ${ }^{*}$ Significant difference between availability of relevant alga and its utilization as decoration or food. Hypnea $=H$. pannosa; Padina $=P$. minor; Sargassum $=S$. thunbergii; Acanthophora $=$ A. spicifera

\section{Selectivity differences among populations}

Calculations of $\mathrm{SE}_{\mathrm{o}}$ values for species from each of the locations showed a trend of increased selectivity (higher $\mathrm{SE}_{\mathrm{o}}$ values) for both Micippa (Fig. 5) and Tiarinia (Fig. 6) from Kochi compared to individuals from Shirahama and Shimoda. When these differences were compared for individual algae species using PSE values, trends in these algae among locations mirrored $\mathrm{SE}_{\mathrm{o}}$ differences for both Micippa (Fig. 5) and Tiarinia (Fig. 6). In the field, Micippa from Kochi had a significantly lower PSE for Corallina pilulifera than Micippa from Shirahama $(\mathrm{p}<0.05)$ or Shimoda $(\mathrm{p}<0.05)$, while Shimoda and Shirahama Micippa did not differ. Micippa from Kochi also had a higher PSE for Hypnea pannosa than Micippa from Shirahama $(p<0.05)$. While PSE means for Jania radiata did vary among locations ( $p=0.0341)$, there were no significant pairwise differences between locations. Although mean PSE values for Ceramium sp. were close to zero (indicating few distinct preferences or avoidances) at all locations, Micippa from Shimoda had a slightly higher preference for Ceramium sp. than Micippa from Kochi $(p<0.05)$, or Shirahama $(p<0.05)$. When PSE values were calculated using \% biomass available (instead of $\%$ cover available), differences between locations were quantitatively similar and trends were statistically stronger; Kochi PSE values were significantly different from Shimoda $(p<0.05)$ and Shirahama $(p<$ 

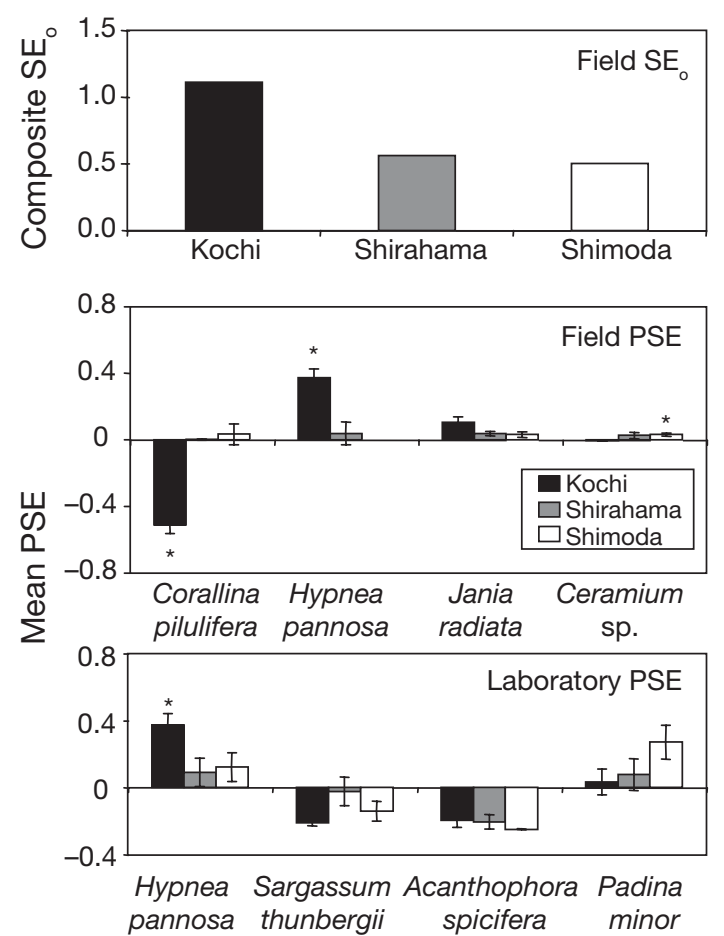

Fig. 5. Micippa platipes. Field selectivity index $\mathrm{SE}_{\mathrm{o}}$, field proportional selectivity index (PSE), and laboratory PSE for crabs at 3 locations in Japan. $\mathrm{SE}_{\mathrm{o}}$ values are composite values and error bars could not be calculated; for PSE values, asterisk indicates that relevant location mean differs significantly from those for other locations

0.05) values for Ceramium sp., Corallina pilulifera, Hypnea pannosa and Jania radiata, while Shimoda and Shirahama did not differ (data not shown).

PSE values from laboratory assays also confirmed the field patterns observed for Micippa (Fig. 5). PSE values for Hypnea pannosa were significantly different among the 3 locations ( $\mathrm{p}=0.0258)$, and pairwise tests indicated that Micippa from Kochi had a higher PSE for H. pannosa than Micippa from either Shimoda ( $\mathrm{p}<$ $0.05)$ or Shirahama $(p<0.05)$, while Shimoda and Shirahama did not differ in their PSE for $H$. pannosa. In terms of food preference, although Micippa from Shimoda preferred to consume Padina minor, there were no significant differences in $P$. minor PSE values for Micippa among the 3 locations ( $p>0.05$ : data not shown). Although Micippa from all 3 locations avoided consuming Sargassum thunbergii in laboratory assays, Shimoda crabs avoided consuming $S$. thunbergii slightly (but significantly) more than crabs from Shirahama and Kochi ( $p<0.05$; data not shown).

Tiarinia from Kochi had a lower PSE for Corallina pilulifera than crabs from Shimoda $(p<0.05)$ or Shirahama ( $p<0.05)$, while Shimoda and Shirahama crabs did not differ (Fig. 6). There were no significant pairwise differences in Padina minor or Jania radiata
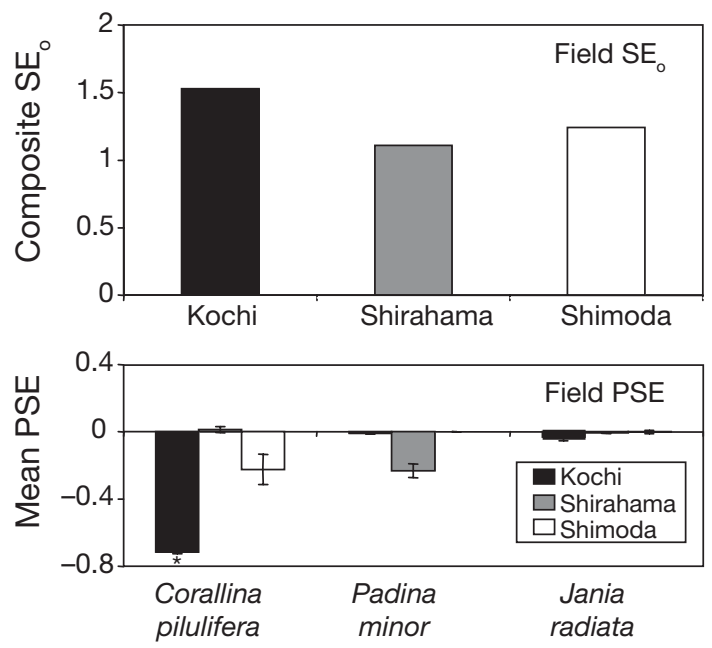

Fig. 6. Tiarinia cornigera. $\mathrm{SE}_{\mathrm{o}}$ and field PSE for crabs at 3 locations in Japan. Further details as in Fig. 5

selectivity among the 3 locations $(p>0.05)$. Results were quantitatively and statistically similar when computed with algal availability as \% biomass.

Measurements of size and decoration quantity of crab species at each location varied slightly between locations (Fig. 7). While Micippa from the 3 locations did not vary significantly in size $\left(F_{2,66}=1.7557, \mathrm{p}=\right.$ $0.1808)$, there were significant differences in decoration quantity $\left(\mathrm{mg} \mathrm{mm}^{-2}\right)$ among locations $\left(F_{3,65}=20.63\right.$, $\mathrm{p}<0.0001$ ), with decoration quantity in Shirahama

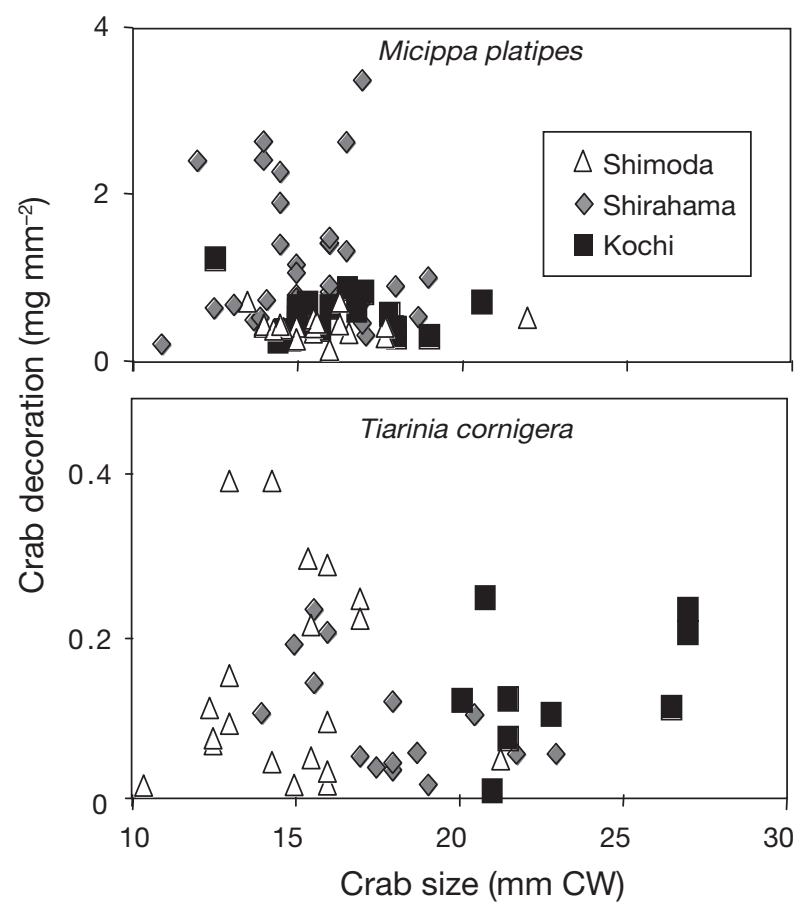

Fig. 7. Micippa platipes and Tiarinia cornigera. Crab decoration quantity $\left(\mathrm{mg} \mathrm{mm}{ }^{-2}\right.$ ) versus crab size (mm carapace width, CW) at 3 locations in Japan 
slightly higher than in Kochi or Shimoda $(\mathrm{p}<0.05)$. However, there were no significant relationships between Micippa size and decoration quantity, either within or among locations. Tiarinia size varied among locations $\left(F_{2,37}=23.07, \mathrm{p}>0.0001\right)$, with Tiarinia from Kochi being larger than Tiarinia from Shirahama or Shimoda ( $p<0.05)$. When decoration quantity $\left(\mathrm{mg} \mathrm{mm}^{-2}\right)$ was regressed against Tiarinia size, there was a significantly negative relationship $(p=0.03)$ in Shirahama, but no significant relationships within each of the other locations or when Tiarinia from all locations were pooled. Despite among-location differences in Tiarinia size, decoration quantity did not vary among locations $\left(F_{2,38}=1.2915, \mathrm{p}=0.2867\right)$.

\section{DISCUSSION}

\section{General trends}

Our results indicate that both Micippa and Tiarinia exhibit geographic variation in decoration selectivity along a latitudinal gradient. At the 2 more northern locations (Shimoda and Shirahama), Micippa and Tiarinia utilized algae for decoration in proportion to their abundance in the field, while crabs from the southernmost location (Kochi) exhibited stronger preferences (Micippa) and stronger avoidances (Micippa and Tiarinia) for particular algae, both in the field and in the laboratory. Specifically, Micippa from Kochi had significantly higher preferences for the red alga Нypnea pannosa than crabs from more northern locations, both in the field and in the laboratory. In Kochi, both Micippa and Tiarinia avoided the coralline alga Corallina pilulifera, while Micippa and Tiarinia in Shimoda and Shirahama used C. pilulifera in proportion to its abundance in the field.

\section{Potential factors influencing selectivity}

As many authors have pointed out (Liszka \& Underwood 1990, Singer 2000, Underwood et al. 2004, Underwood \& Clarke 2005), calculations of preference and avoidance are not independent of each other, and it is difficult to discern whether avoidance of one material is driven by a strong preference for another, or vice versa. For example, in Kochi, Micippa's strong preference for Hypnea pannosa was accompanied by a strong avoidance of the dominant alga Corallina pilulifera. However, in laboratory assays where availability was standardized, Micippa from Kochi still had significantly higher preferences for $H$. pannosa. than Micippa from the other 2 locations, suggesting preferences might be driven more by intraspecific differ- ences in preference for $H$. pannosa. For Tiarinia in Kochi, avoidance of $C$. pilulifera did not appear to be driven by strong preferences for other algae, as Tiarinia used the other algae in approximate proportion to their abundance in the field.

Strong preferences or avoidances for certain decoration materials in decorator crabs are thought to be linked to many factors, including chemical defense (Stachowicz \& Hay 1999), food preferences (Kilar \& Lou 1986, Woods \& McLay 1994), handling time (Stachowicz \& Hay 1999, Cruz-Rivera 2001), and/or variation in seasonal availability of decoration materials (Sato \& Wada 2000). Although many of these hypotheses are plausible, no single hypothesis adequately explains the geographic differences in selectivity we saw in our experiment. There is no record of chemical defense in Hypnea pannosa that might confer predator protection. It is unlikely that food preferences are driving decoration preferences, since preferences for food and decoration were decoupled, both in our study and in a previous study of Micippa and Tiarinia (Sato \& Wada 2000). Handling time considerations might be important; morphology has been known to strongly influence food selection in grapsid crabs (Kennish \& Williams 1997), and some authors suggest that handling time constraints could influence preferences in decorator crabs (Stachowicz \& Hay 2000, Cruz-Rivera 2001). Indeed, the fleshy turf morphology of $H$. pannosa species may be easier to cut and handle than Corallina pilulifera, which is calcified. However, handling time does not explain Micippa's continued preference for $H$. pannosa during assays in Shirahama, where Micippa were also offered the non-calcified algae Acanthophora spicifera and Padina minor yet still preferred $H$. pannosa. Handling time could also affect preference if crabs were physically unable to decorate with a material (e.g. C. pilulifera), since they would appear to 'avoid' it even in locations where it was more abundant. However, while Tiarinia and Micippa both avoided C. pilulifera in Kochi, they decorated with this alga readily in Shimoda, and both utilized C. pilulifera during winter and fall months in Shirahama (Sato \& Wada 2000), suggesting that this alga is an 'acceptable' material with which to decorate. However, it is possible that avoidance of $C$. pilulifera could have been due to unanticipated (and unmeasured) intraspecific variation in algal morphology among locations (e.g. more calcified in Kochi).

\section{Seasonal differences}

In Shirahama, both Tiarinia and Micippa are known to vary their decoration choices over a season, and it is possible that latitudinal differences among locations 
mimic seasonal variation within a location. In Shirahama, Micippa and Tiarinia preferentially use Corallina pilulifera in winter (Sato \& Wada 2000), and in our experiment run in summer (when C. pilulifera is rare), crabs used Hypnea pannosa, Padina minor, and Acanthophora spicifera in proportion to their abundances. If crabs had fixed ranked preferences for algae, the identity of their top-ranked algae could shift depending on which algae co-occur within a season. For example, if Micippa preferred H. pannosa, C. pilulifera, and Sargassum thunbergii (in that order), their top-ranked alga for decorating could be $C$. pilulifera (when only $C$. pilulifera and $S$. thunbergii are present), and $H$. pannosa (when only $H$. pannosa and C. pilulifera are present). This does not appear to explain Micippa's preferences for $H$. pannosa: crabs from Kochi preferred $H$. pannosa in a variety of contexts, from field surveys (when $H$. pannosa and C. pilulifera were present) as well as laboratory assays in Shirahama (when H. pannosa, P. minor, A. spicifera, and S. thunbergii were present), suggesting that preference for $H$. pannosa might be a more fixed feature of southern Micippa. Latitudinal differences in seasonality could also affect preferences for $H$. pannosa; for example, it might be adaptive for southern crabs to develop fixed preferences for this alga (if it is reliably available all year round), but for more northern crabs to have more plastic decoration preferences (if algal assemblages shift seasonally). Although there is little known about Micippa from other locations, Dudgeon (1980) noted that Hypnea spp. comprised up to $90 \%$ of the decoration material on Micippa individuals in Hong Kong, suggesting that this preference may be common in other populations of this crab south of Japan.

\section{Implications}

Increases in intraspecific decoration selectivity (stronger preferences and/or avoidances) with decreasing latitude could indicate a general pattern of decreases in niche breadth at lower latitudes, as hypothesized by MacArthur (1972). Regionally, many species thought of as net ecological generalists along their range can be specialists in some locations, and such patterns underscore the importance of scale in understanding species-level patterns of specialization (Fox \& Morrow 1981). Although there have been few investigations of how intraspecific niche width might vary with latitude, especially in marine species (but see Stachowicz \& Hay 2000), many marine species have wide geographic ranges throughout which behavior is variable (Fawcett 1984, Stachowicz \& Hay 2000, Sanford et al. 2003, Sotka et al. 2003). The same factors hypothesized to decrease niche width (i.e. increased specialization) among species, e.g. greater population stability, less seasonality of resources, could theoretically operate within a species, driving intraspecific variation in niche width. Investigating such patterns requires investigation of niche width and resource use on many scales. Variation in specialization and preference can be an important component of the ecology (influencing the outcome of species interactions) and evolution (promoting local adaptation) of a species. Examining geographic variation in behavior in a comparative context (e.g. by comparing the responses of 2 species to shared environmental conditions) can further complement geographic studies of behavioral variation.

Acknowledgements. The authors thank Dr. K. Wada of Nara Women's University for his invaluable help in providing laboratory space, field support and experimental advice, as well as organizing contacts at different locations. Local collaborators at different locations helped greatly during fieldwork, including Dr. S. Wada (Usa Marine Biological Institute) and Dr. M. Aoki (Shimoda Marine Research Center). Dr. M. Ohno and Dr. K. Tanaka helped with algae identifications. Funding was provided in part by the National Science Foundation Summer Program in Japan fellowship awarded to K.M.H. Dr. J. J. Stachowicz, A. R. Hughes, J. M. Davis, and 2 anonymous reviewers gave comments on earlier drafts that greatly improved the manuscript.

\section{LITERATURE CITED}

Alldredge JR, Ratti JT (1986) Comparison of some statistical techniques for analysis of resource selection. J Wildl Manag 50:157-165

Alldredge JR, Ratti JT (1992) Further comparison of some statistical techniques for analysis of resource selection. J Wildl Manag 56:1-9

Conover WJ (1999) Practical nonparametric statistics, 3rd edn. John Wiley \& Sons, New York

Cruz-Rivera E (2001) Generality and specificity in the feeding and decoration preferences of three Mediterranean crabs. J Exp Mar Biol Ecol 266:17-31

Downes SJ, Adams M (2001) Geographic variation in antisnake tactics: the evolution of scent-mediated behavior in a lizard. Evolution 55:605-615

Dudgeon D (1980) Some inter- and intraspecific differences in the decorating patterns of majid crabs (Crustacea: Decapoda) from the coastal waters of Hong Kong. In: Morton BS, Tseng CK (eds) Proceedings of the First International Marine Biological Workshop: the marine flora and fauna of Hong Kong and Southern China. Hong Kong University Press, Hong Kong, p 825-835

Endler JA, Houde AE (1995) Geographic variation in female preferences for male traits in Poecilia reticulata. Evolution 49:456-468

Fawcett MH (1984) Local and latitudinal variation in predation on an herbivorous marine snail. Ecology 65:1214-1230

Foster SA (1995) Understanding the evolution of behavior in threespine stickleback: the value of geographic variation. Behaviour 132:1107-1129

Foster SA (1999) The geography of behaviour: an evolutionary perspective. Trends Ecol Evol 14:190-195 
Fox LR, Morrow PA (1981) Specialization: species property or local phenomenon? Science 211:887-893

Ivlev VS (1961) Experimental ecology of the feeding of fishes. Yale University Press, New Haven

Kennish R (1997) Seasonal patterns of food availability: influences on the reproductive output and body condition of the herbivorous crab Grapsus albolineatus. Oecologia 109: 209-218

Kennish R, Williams GA (1997) Feeding preferences of the herbivorous crab Grapsus albolineatus: the differential influence of algal nutrient content and morphology. Mar Ecol Prog Ser 147:87-95

Kilar JA, Lou RM (1986) The subtleties of camouflage and dietary preference of the decorator crab Microphrys bicornutus Decapoda Brachyura. J Exp Mar Biol Ecol 101:143-160

Liszka D, Underwood AJ (1990) An experimental design to determine preferences for gastropod shells by a hermit crab. J Exp Mar Biol Ecol 137:47-62

MacArthur RH (1972) Geographical ecology. Princeton University Press, Princeton, NJ

Neu CW, Byers CR, Peek JM (1974) A technique for analysis of utilization availability data. J Wildl Manag 38:541-545

Raffa KF, Havill NP, Nordheim EV (2002) How many choices can your test animal compare effectively? Evaluating a critical assumption of behavioral preference tests. Oecologia 133:422-429

Rice WR (1989) Analyzing tables of statistical tests. Evolution 43:223-225

Sakai T (1965) The crabs of Sagami Bay. East-West Center Press, Honolulu, HI

Sanford E, Roth MS, Johns GC, Wares JP, Somero GN (2003) Local selection and latitudinal variation in a marine predator-prey interaction. Science 300:1135-1137

Sato M, Wada K (2000) Resource utilization for decorating in three intertidal majid crabs (Brachyura: Majidae). Mar Biol 137:705-714

Singer MC (2000) Reducing ambiguity in describing plantinsect interactions: 'preference', 'acceptability' and 'electivity'. Ecol Lett 3:159-162

Sotka EE, Hay ME (2002) Geographic variation among herbi-

Editorial responsibility: Roger Hughes (Contributing Editor), Bangor, UK vore populations in tolerance for a chemically rich seaweed. Ecology 83:2721-2735

Sotka EE, Wares JP, Hay ME (2003) Geographic and genetic variation in feeding preference for chemically defended seaweeds. Evolution 57:2262-2276

Stachowicz JJ, Hay ME (1999) Reducing predation through chemically mediated camouflage: indirect effects of plant defenses on herbivores. Ecology 80:495-509

Stachowicz JJ, Hay ME (2000) Geographic variation in camouflage specialization by a decorator crab. Am Nat 156: $59-71$

Steel RGD, Torrie JH, Dickey DA (1997) Principles and procedures of statistics: a biometrical approach, 3rd edn. McGraw-Hill, Boston, MA

Thanh PD, Wada K, Sato M, Shirayama Y (2003) Decorating behaviour by the majid crab Tiarinia cornigera as protection against predators. J Mar Biol Assoc UK 83: 1235-1237

Trussell GC (2000) Predator-induced plasticity and morphological trade-offs in latitudinally separated populations of Littorina obtusata. Evol Ecol Res 2:803-822

Trussell GC, Ewanchuk PJ, Bertness MD (2003) Traitmediated effects in rocky intertidal food chains: predator risk cues alter prey feeding rates. Ecology 84:629-640

Underwood AJ, Clarke KR (2005) Solving some statistical problems in analyses of experiments on choices of food and on associations with habitat. J Exp Mar Biol Ecol 318: $227-237$

Underwood AJ, Chapman MG, Crowe TP (2004) Identifying and understanding ecological preferences for habitat or prey. J Exp Mar Biol Ecol 300:161-187

Werner EE, Peacor SD (2003) A review of trait-mediated indirect interactions in ecological communities. Ecology 84: 1083-1100

Wicksten MK (1993) A review and a model of decorating behavior in spider crabs (Decapoda, Brachyura, Majidae). Crustaceana 64:314-325

Woods CMC, McLay CL (1994) Use of camouflage materials as a food store by the spider crab Notomithrax ursus (Brachyura: Majidae). N Z J Mar Freshw Res 28:97-104

Submitted: September 21, 2005; Accepted: March 13, 2006 Proofs received from author(s): October 18, 2006 